\title{
Feasibility study of straw on the application in green buildings
}

\author{
Huang Qunyi ${ }^{1, a}$, Lei Du ${ }^{2, b}$ \\ ${ }^{1}$ Southwest Jiaotong University, Emeishan, China \\ 2 Southwest Jiaotong University, Emeishan, China

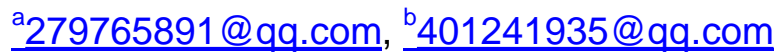

Keywords: straw; green buildings; feasibility study.

Abstract. In order to solve the problem about air pollution caused by straw burning and improve comprehensive utilization of straw, the paper analyses feasibility study of straw on the application in green buildings based on the survey about the existing situation of straw in rural areas of Emeishan city, Sichuan province. It promotes further using with various levels and ways.

\section{Introduction}

Straw,a general term of stem or leaf(spike) part of mature crop(figure. 1), usually refers to the remaining part of wheat, rice, corn, potato, cotton, sugarcane and other crops after harvest, generally can be used for growing animal, renewable bio-oil and good building materials, etc. It has a great economic and practical value. In the past, due to the lack of technology and backward concepts, straw was usually burned or discarded directly in the farmland(figure. 2), causing a great waste of precious natural resources. Especially, a large number of straw burned in the open air with strong bad smoke, which not only polluted air, but was harmful to human healthy. At the same time, burning had a big effect on road traffic and aviation safety. It caused traffic accidents, and threatened our safety. Therefore, government in China has issued some regulations to forbid burning straw, and lists an important task about comprehensive utilization of straw to prevent air pollution. Today straw is mainly used in planting (i.e. fertilizer utilization, figure. 3), breeding (i.e. feed utilization, figure. 4), paper making and so on. So how to apply it is still a problem needed to be sloved. In order to further expand the field of application of straw and effectively improve the comprehensive utilization of straw, the paper considers straw as a renewable, high-quality natural green materials for buildings. For this purpose, we interviewed lots of people and got a survey about the current situation of comprehensive utilization of straw in rural and production condition of straw company, so as to study the feasibility on application of straw, and explore the way of reasonable use for green buildings.

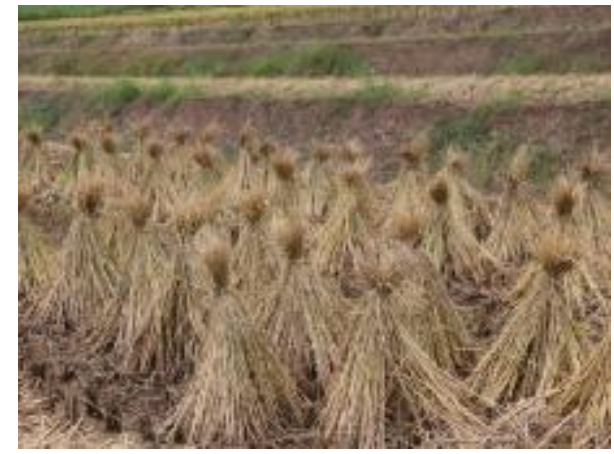

Fig. 1 Rice straw

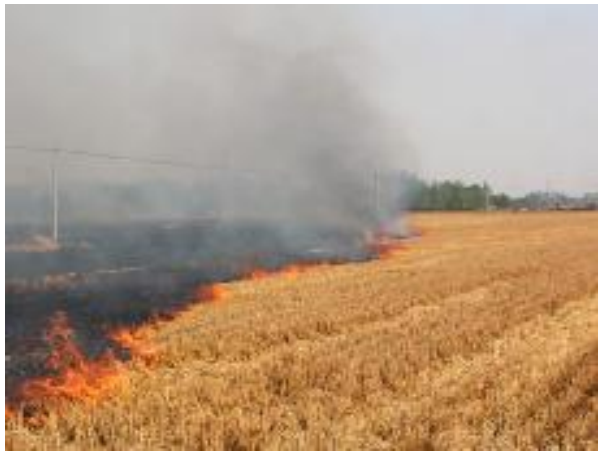

Fig. 2 Straw burning 


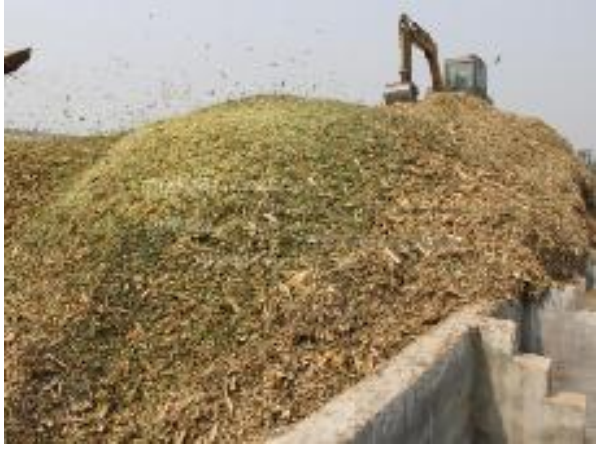

Fig. 3 broken straw

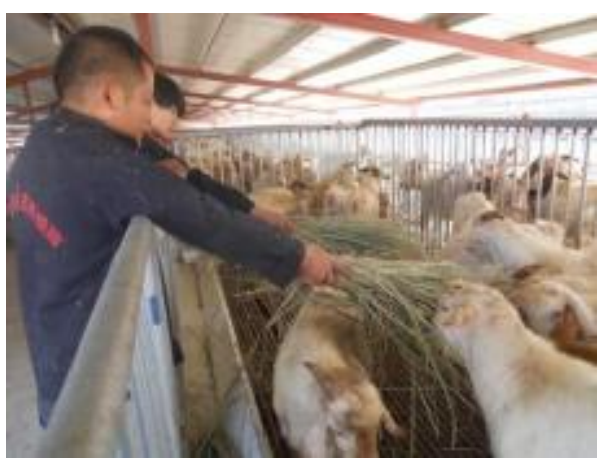

Fig. 4 Straw fodder

\section{The Situation of Using Straw in Rural Areas}

\section{Survey Content.}

Survey's Object. The site in paper chose Emei city in Sichuan province for research region where people lived and worked nearby.Firstly, ranked the number of people by the proportion of rural population in Emei city,and chose districts which have a mass of floating population for sample.Then drew an item at random in the sample area. According to statistical analysis, finally six towns were chosen as the survey objects: huangwan, wuxiangang, pengqiao, shuangfu, guihuaqiao and luomu.

Survey's Time. From November to December in 2015.

Survey's Method. Considering rural residents' habits of life and standard of culture, the major investigation in the survey is by questionnaire, combined with interview.

Survey's Questions. Combined with the previous research and the situation in rural areas in Sichuan province, the problem of the survey mainly includes: types of crops grown by farmers, dispose method of crop straw, the attitude of burning straw, reasons for burning straw directly, Knowing of enterprises which recycle straw etc. Through the survey of these 5 questions, it is helpful to analyze the reason why farmers tend to burn straw.And it is helpful to take the corresponding measures to provide direction to straw applications in green buildings.

Survey's Analysis. A total of 220 questionnaires were issued in the survey, and recycled effective questionnaire 203, and the percent of pass was about 92.3\%. The survey data was recorded by each survey members, and collected it and numbered it. At last, Excel and MATLAB software were used to analyze the quantitative data.

Survey's Results. Through the statistical analysis on the survey of 203 eligible questionnaires, results of the survey are shown in table 1 .

Table 1 The basic situation of straw use

\begin{tabular}{cccc}
\hline \multicolumn{2}{c}{ The basic use situation of straw } & $\begin{array}{c}\text { Frequency } \\
\text { (person) }\end{array}$ & $\begin{array}{c}\text { percentage } \\
(\%)\end{array}$ \\
\hline \multirow{2}{*}{ Main crops } & Rice & 157 & 77.3 \\
& Corn & 35 & 17.2 \\
Process method & The others & 11 & 5.4 \\
\hline & Burning derectly & 86 & 42.3 \\
& return straw to the farmland & 65 & 32.0
\end{tabular}


Making firewood

resource utilization

\begin{tabular}{|c|c|c|c|}
\hline & The others & 8 & 3.9 \\
\hline \multirow{3}{*}{$\begin{array}{l}\text { The attitude about } \\
\text { burning straw }\end{array}$} & Yes & 35 & 17.2 \\
\hline & No & 113 & 55.7 \\
\hline & whatever & 53 & 26.1 \\
\hline \multirow{4}{*}{$\begin{array}{l}\text { The reasons why burn } \\
\text { straw directly }\end{array}$} & Easy to deal with & 93 & 45.8 \\
\hline & $\begin{array}{l}\text { Thing left by bruning } \\
\text { can fertilize farmland }\end{array}$ & 55 & 27.1 \\
\hline & No time & 40 & 19.7 \\
\hline & The others & 15 & 7.38 \\
\hline \multirow{3}{*}{$\begin{array}{l}\text { Knowing of } \\
\text { enterprises which } \\
\text { recycle straw }\end{array}$} & $\begin{array}{l}\text { There are enterprises recycling } \\
\text { straw around }\end{array}$ & 16 & 7.8 \\
\hline & $\begin{array}{l}\text { There aren`t enterprises recycling } \\
\text { straw around }\end{array}$ & 147 & 72.4 \\
\hline & $\begin{array}{l}\text { Don't know whether there exist } \\
\text { enterprises recycling straw around }\end{array}$ & 40 & 19.7 \\
\hline
\end{tabular}

From the table 1, we know the main situation of straw use in Emei, specific analyses are as follows:

The Type of Crops Planted by Farmers. In the survey, there were $77.3 \%$ of people mainly to plant rice, secondly, some planted corn. The surplus of straw was almost the rice straw, which was consistent with the situation of surplus straw almost in the south rural area of China. It indicates that it should be considered first that rice straw is thought of as the main building materials research object in the application of straw in green buildings. It's significative to research its plant characteristics, chemical composition and effect on structural performance when straw is combined with concrete (such as: mechanical property, thermal and sound insulation property)

Process Method of Crop Straw. In the way to deal with crop straw, $42.3 \%$ people chose to burn straw directly, and 32\% returned straw back to the farmland. However, in the rural area, with the gradual application of new type of fuel such as liquefied petroleum gas and natural gas and so on, the traditional way of using straw as a burning fuel has already decreased to $18.7 \%$. Thus it can be seen that the way of dealing mainly rely on burning or returning back to the farmland. Straw burning still considers as a primary way to deal with it, which causes a series of problem like air pollution, human health, road traffic and aviation safety etc. Therefore, it's an important research work to apply straw with further levels and ways, to solve the problem about recycling. 
The Attitude about Straw Burning. 55.7\% person didn't support to burn straw, and many villagers can realize that straw burning have a bad influence on atmosphere environment and transportation. However, there were $26.1 \%$ people taking no care about burning straw, and even about $17.2 \%$ people still chose this way to deal with straw. Therefore, it's necessary for government to enhance the publicity and education on forbiding burning straw, considering villagers'living condition and education in rural area

The Reasons Why Burn Straw Directly. Although most villagers can realize their mistake about burning straw, they still choose to burn in practice. From the survey, the direct reason is for convenience during the labour time. Furthermore, it isn't easy for farmers to get profits from the straw left. Due to lack of specific punishment and supervision, they still ignore the environmental protection even though government of China has already forbidden burning straw. At the same time, it also reflects that the way of recycling straw isn't clear enough so as to it can't be recycled immediately. So farmers choose to burning directly for convenience.

Knowing of Enterprises which Recycle Straw. Although government has already forbidden burning straw, they can't develop the effective way and platform to recycle. In the survey, up to $72.4 \%$ people mentioned explicitly that there didn't exist the company to recycle straw arround. About $19.7 \%$ people didn't know whether existed, and only $7.8 \%$ people knew about the company on recycling straw. However, the company does't develop very well. A lack of recycling is also an important reason that farmers burn straw directly.

\section{Feasibility Study of Straw on the Application of Green Buildings.}

On the basic of previous survey, this section talks about the feasibility study of straw of green buildings on application form, cost and prospect and so on. Results are as follows:

Application Form. Straw is rich in nitrogen, phosphorus, potassium, calcium, magnesium and organics etc, which is a multi-purpose and renewable biological resources. As a building material, it coincides with construction idea that the green building make full use of natural resources of the environment. Set the rice straw (the main chemical components are shown in table 2) for example, cut off some fiber materials into pieces(figure. 5), and mix the magnesite cement into it as the cementing material, finally stir enough forming the straw board (figure. 6), used as a thermal insulation layer in the middle of straw wire aircraft sandwich panels(figure. 7). Besides, mix the rice straw pieces, water, cement, dinas and admixture and so on with a certain percentage, and casting building blocks (figure. 8)and keep it in good condition, mainly used for green building walls. Not only can it be used for structural components like walls, but also made for building ornament like floors, doors, windows etc. It can take full advantage of its environmental-friendly, renewable, adaptive and low-cost characteristics. 

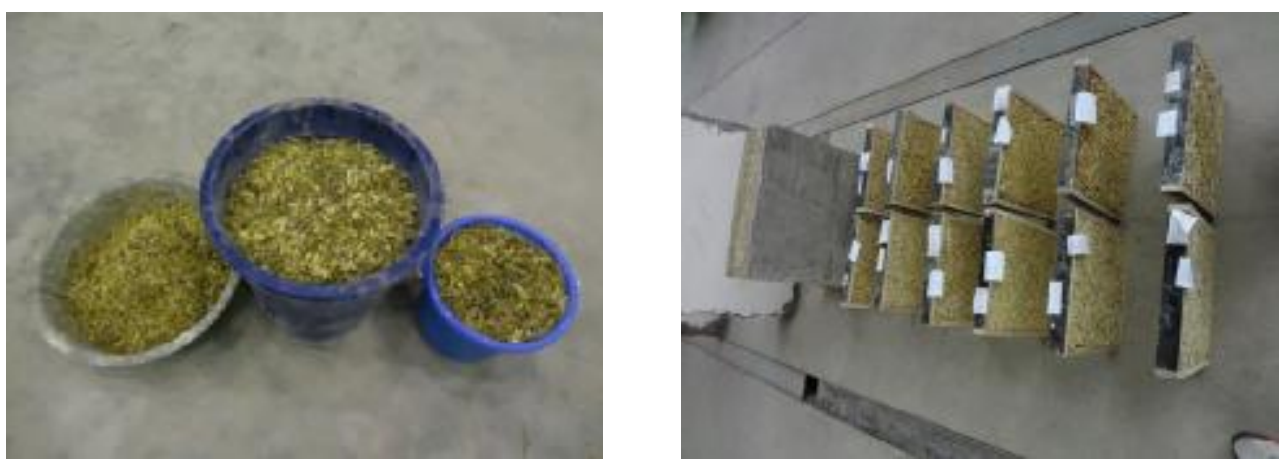

Fig. 5 broken straw

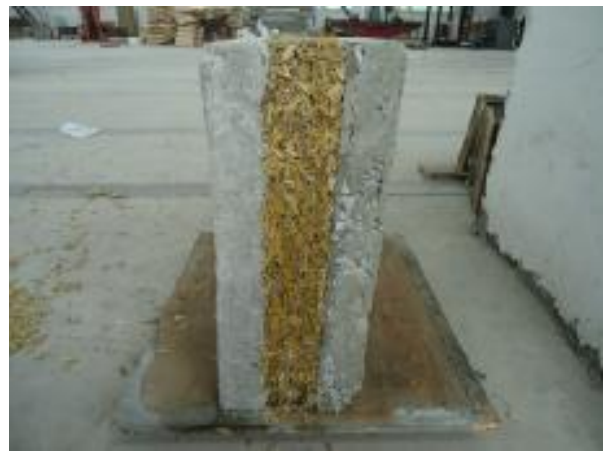

Fig. 7 Straw wire aircraft sandwich panels
Fig. 6 Straw board

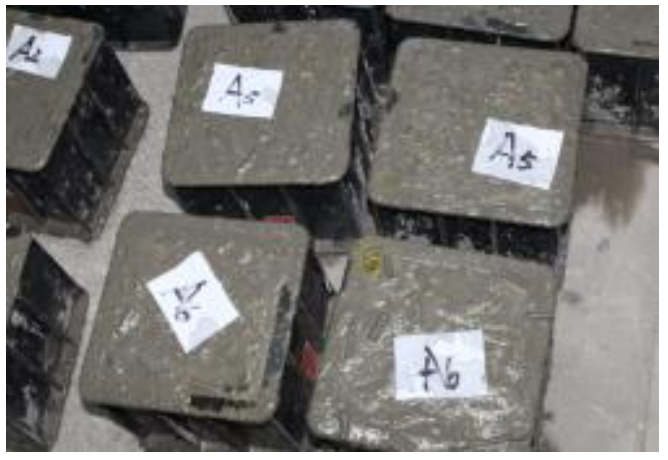

Fig. 8 Straw concrete block

Application Cost. In the survey, $74.9 \%$ respondents can accept the price of recycling straw below $200 \mathrm{RMB}$ per ton. $22.2 \%$ think it resonable at the price of 200 300 RMB per ton. The others have another choice. After comprehensive thinking, farmers expected straw recycling price is about 220 $\mathrm{RMB}$, which can be accepted by most companies. It indicates that straw has the advantage of low price except natural, renewable, environmental characteristics as a building material.

Application Prospect. Green building uses straw as building materials, which not only has advantages of rich raw-materials, low cost, the use of safe, light density, high strength, small coefficient of thermal conductivity and convenient construction, but also can increase the utilization rate of straw and improve environment to promote sustainable development. It has great application

value $^{[1]}$. For example, Straw wire aircraft sandwich panels combine reinforced concrete with straw to form a composite structure used in green building. The structure both can improve the seismic performance and have a good effect of fire prevention, anti-corrosion, moth proof, etc. At present, China greatly promotes construction of industrialization,especially prefabricated concrete construction system which is suitable for industrialized production. Straw wire aircraft sandwich panels itself belong to prefabricated composite components especially suitable for it. Therefore, with the application and popularization of fabricated structure, combined with the current development trend of construction and residence industrialization, straw wire aircraft sandwich panels have very extensive application prospect in the construction as the representive of the straw building.

\section{Conclusion and Advice}

According to the survey of straw utilization situation in rural areas, and analyses on feasibility of its application in green buildings. We get the summary, and give some corresponding advices. 
Rice straw is a primary surplus straw in rural areas. It has a lot of production. We should consider firstly to make it become an important raw material of green buildings. Then we can study its plant characters, chemical composition, material performance (such as: mechanical performances, temperature and sound insulation, etc.).

Straw burning is still the main method on dealing with straw in rural areas. Therefore, government should emphasis on publicity and education of prohibiting straw burning, and implement some necessary punitive measures. At the same time, they should increase support of straw utilization enterprise. Moreover, they can set up effective channel to recycle straw between farmers and enterprises.

Straw is a kind of natural renewable resources. It can be used for green buildings as a building material. It also can be made into straw wire aircraft sandwich panels, straw concrete block, straw floor, straw window etc. It has the advantage of abundant raw materials, low cost, the use of safe, light density, high strength, small coefficient of thermal conductivity, convenient construction, etc. In the future, I believe it must have broad application prospects.

\section{References}

[1] Huang Qunyi, Xiong Feng*, Fan Kui, He Yuchuan.An experimental study on thermal insulation performance of straw wire aircraft sandwich panel, Advanced Materials Research,Vol. 639-640, pp1307-1312, 2013, Advances in Civil Infrastructure Engineering.

[2] Huang Qunyi; Xiong Feng; He Shilong; Du Shubi. Experimental research on seismic performance of new type GSZ -walls. Energy Education Science and Technology Part A Energy Science and Research, 2014 Vol.3(1):1459-1464.

[3] Wang Baozhen; Li Jiandong. Application research of crop straw in the construction of small towns. Construction of Small Towns, 2010.02,the second issue: 67-69.

[4] Huang Qunyi, Lei Du, Wang Ji, Yang Yiwei, Bao Ning. Research on the application of straw in rural buildings. 《Advances in Engineering Research》, 2015 Vol.44(1):432-436.

[5] Huang Qunyi. A new 3D seismic energy conservation rural structure research.Sichuan University, 2013.

[6] Qunyi Huang, Feng Xiong, Qi Ge, Yan Yin, Ning Zhou. Structural Behavior of a New GSZ Panel Under Lateral Loads. Advanced Materials Research, v 538-541, 1762-1768, 2012, Materials

Processing Technology II

[7] Yin Yan; Xiong, Feng; Huang, Qunyi. Experimental research on seismic performance of new type GSZ walls. Sichuan Building,2012.02, Vol.23(1): 206-208. 